Article

\title{
Guilt-Tripping: On the Relation between Ethical Decisions, Climate Change and the Built Environment
}

\author{
Paulina Prieto de la Fuente \\ Department of Architecture and Built Environment, Lund University, 22362 Lund, Sweden; \\ E-Mail: paulina.prieto_de_la_fuente@arkitektur.Ith.se
}

Submitted: 29 May 2020 | Accepted: 22 September 2020 | Published: 12 November 2020

\begin{abstract}
The curiosity of how the built environment, implicitly and explicitly, affects how citizens and users make choices in their everyday life related to climate change is on the rise. If there is a nicely designed bike lane, the choice to bike to work is much more easily taken than if the only option is a densely trafficked road. But which responsibility does the built environment have for citizens to be as climate neutral as possible and, in extension, who should it burden? Is it the individual user, the designer, the planner, the policymaker or global politics? Media is playing an important and complicated role here; it works both as a source of information and as a trigger, instigating both feelings of guilt, fear, and shame in order to set change in motion. In this article, I will discuss everyday climate-related decision-making fuelled by shame and guilt, drawing on Judith Butler's writings on ethical obligations and narrating it with findings from a mapping study of daily transportation routes that I conducted in a middle-class suburb outside of Lund, in Sweden. There appears to be a dissonance between the relatively high knowledge about one's responsibility concerning climate change and the limited space to manoeuvre in everyday life. Even though shame and guilt may be driving forces to make decisions, the possibility to imagine and to change needs to be expanded.
\end{abstract}

\section{Keywords}

built environment; climate change; climate ethics; ethical responsibility; guilt; shame; urban design

\section{Issue}

This article is part of the issue "Built Environment, Ethics and Everyday Life" edited by Mattias Kärrholm (Lund University, Sweden) and Sandra Kopljar (Lund University, Sweden).

(C) 2020 by the author; licensee Cogitatio (Lisbon, Portugal). This article is licensed under a Creative Commons Attribution 4.0 International License (CC BY).

\section{Introduction}

For reasons unfathomable to the most experienced prophets in Maycomb County, autumn turned to winter that year. We had two weeks of the coldest weather since 1885, Atticus said. Mr Avery said it was written in the Rosetta Stone that when children disobeyed their parents, smoked cigarettes and made war on each other, the seasons would change: Jem and I were burdened with the guilt of contributing to the aberrations of nature, thereby causing unhappiness to our neighbours and discomfort to ourselves. (Lee, 1960/2002, p. 72)

This is a fictional quote that expresses popular belief and burdens children with guilt. By doing so, it neatly captures the topics that this article wishes to discuss: the level of responsibility that lands on the users of the built environment concerning climate matters and how shame can play a role in everyday decision-making. This article is driven by a curiosity concerning how the built environment, implicitly and explicitly, affects how citizens and users make choices in their everyday life related to climate change. If there is a nicely designed bike lane, the choice to bike to work is much more easily taken if the only option is a densely trafficked road. But what is the role of the built environment in encouraging citizens to be as climate neutral as possible and, in extension, where should this responsibility be placed? Buildings, roads, walls, bridges and other built elements can connect, disconnect, produce and perform through their use and thereby become important actors in many 
everyday choices as they are activated in social and political settings (Yaneva, 2017, p. 72).

Catastrophic images and reports communicated by the media might be overwhelming, leaving us with a desire to act and to change quickly. In Precarious Life, Judith Butler $(2004,2011)$ writes about the rage and grief invoked in individuals through images of war reported by the media, she wonders if we must be overwhelmed to act (Butler, 2011, p. 3). In this article, I will discuss how shame and guilt may contribute to climate-related decision-making in everyday life. I will follow Butler's line of reasoning on ethical obligations and narrate it with findings from a mapping study of daily transportation routes that I conducted in a middle-class suburb outside of Lund, in Sweden. A tentative finding in the empirical study is that the respondents, in general, had a relatively high awareness of their responsibility concerning climate change and a rather narrow possibility of change in their everyday lives. This discrepancy must be addressed, and room must be made to increase the possibility of making climate-friendly adjustments in transportation routes.

\section{Everyday Transportation}

The mapping study took place in Stångby, which is an expanding village north of Lund, in the south of Sweden. Figure 1 shows a view over the newest part with resi- dential single housing. First, in May 2019, a flyer was distributed in residents' mailboxes with information about the study and a call for participants. Out of the 200 flyers, 10 people answered that they wanted to take part. A few weeks later, in June 2019, I went back to distribute the packs with maps and questionnaires, I handed out 40 packs in total, to the ones that had responded to the call and to people I had talked to during my observational visits to the location. I gave some of the respondents' double packs, encouraging them to pass one of them on to a partner, a neighbour or a friend. The packs included maps in two scales; one focused on the area of Stångby and Lund, and one zooming out to include a larger region with Malmö in the south and Landskrona in the north. The instructions were to map out everyday routes in different colours depending on whether it was work-, consumption- or leisure-related and to make notes of what time and what type of transportation was used from Monday to Sunday, consecutively. There was also a questionnaire included in the pack with questions about decisions concerning transportation and a prepaid envelope to send the material back to me. I received 14 packs back with maps that were filled out between June and September. In this article, I will mainly use examples from the questionnaires and comments made in the margins on the maps. I have also followed letters to the editor concerning climate change and everyday life in the Swedish newspapers (mainly Sydsvenska Dagbladet

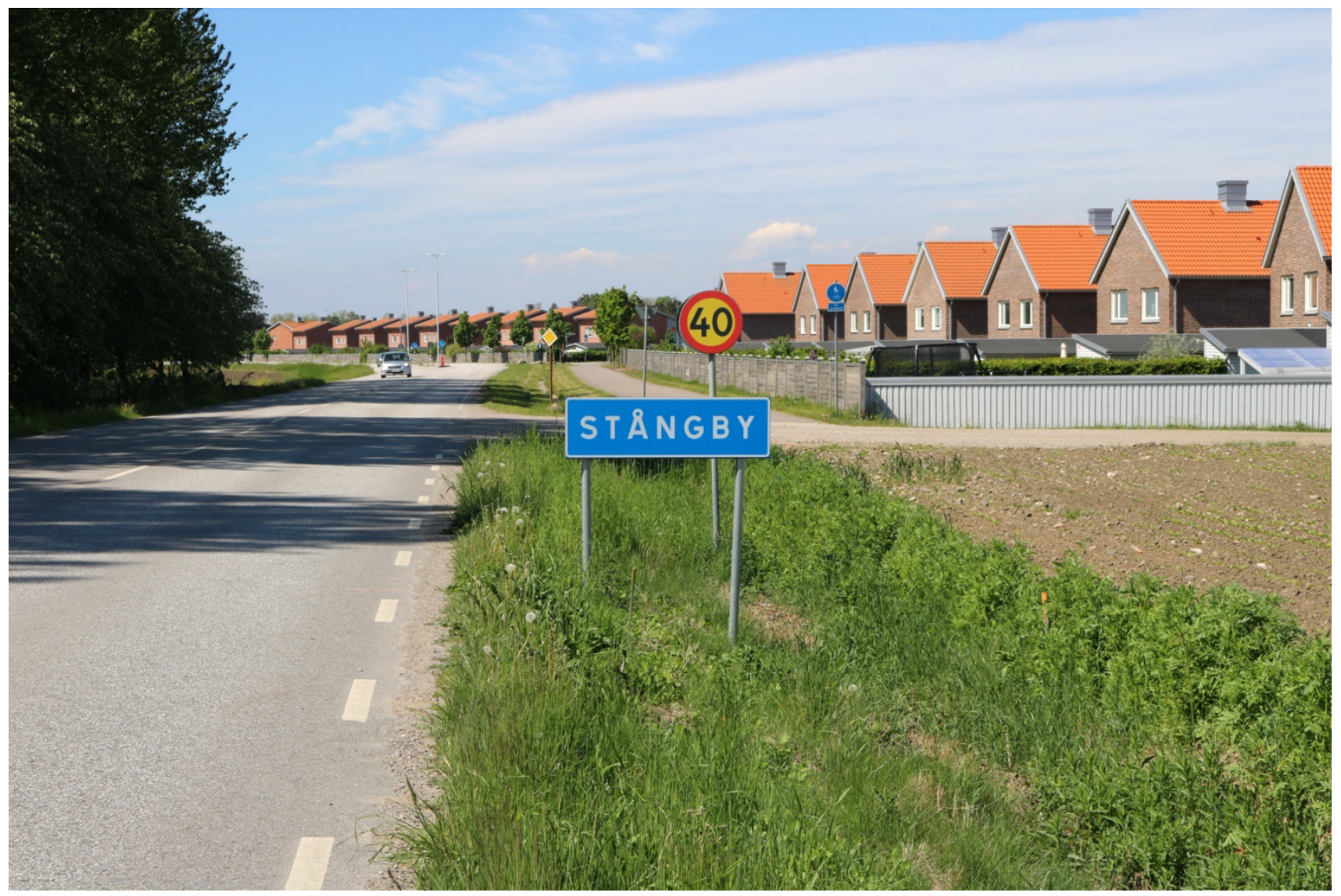

Figure 1. The view from the north entrance to Stångby. Source: Author. 
and also Dagens Nyheter). I am using the empirical material from the mapping study qualitatively. The sample is rather small and could perhaps be considered biased since the packs were distributed to some extent between friends and family. In this article, the material is used mainly to contribute with situatedness to a wider ethical discussion.

\section{Ethical Obligations}

It is important to bear in mind that climate change is an international and intergenerational problem that strikes differently over space and time, and even if it is a problem for everyone, it is far from just. The western world is responsible for a major part of $\mathrm{CO}_{2}$ emissions, however, at the moment, the effects are more acute in, for example, countries of the African continent (Williston, 2019, p. 71). Butler's discussion on ethical obligations in hard times is based on war, specifically violence sanctioned by the US government in the years after the attacks on the Twin Towers in New York on September 11th, 2001. Butler's reasoning is based on the individual citizen's responsibility, drawing on the work of Emmanuel Levinas and Hannah Arendt. Still, it does not allow anyone to be singled out but, on the contrary, to always be bounded in relation to the other (Butler, 2004, 2011, 2016). Even if the geographical distance spans over continents, we have ethical obligations to one another, we also have ethical obligations to the ones in our proximity, even those with whom we did not choose to live (Butler, 2011, p. 15). By writing this, she claims that what happens nearby also happens far away, and that involuntary cohabitation is prerequisite for equality but also precarity.

Butler describes how anger and grief can be dangerous if used as an excuse for governments or people in power to make hasty decisions, ideas that are also relevant in a discussion on ethical obligations concerning climate change. If grieving is to be feared, the fears can, in turn, become starting points for impulsive decisionmaking and quick fixes, leading to the elusive idea of restoring everything to a former order, or rather a fantasy that the world was once orderly (Butler, 2004, p. 29).

I am humble to the fact that the translation from war to climate change may not be immediate, but many of the preconditions are similar. For example, the issues of distance and proximity, even if the effects of our pollution do not necessarily have a direct effect on our everyday life, we are informed by the media, measurements, scientists, that there are effects that affect somebody else's everyday life. Carbon pollution does not respect national or political boundaries (Williston, 2019, p. 70) and that knowledge in itself should come with ethical obligations.

In some countries, the effects of climate change are so severe that it makes places unliveable and causes migration (Williston, 2019, p. 17). As in war, there is a shared precariousness that comes with the uncertainty of what effects we will witness in the near future and where it will strike hardest. Whereas war usually plays out between two or more nation-states and alliances, climate change defies national borders; it is global and will affect us all to different degrees. The inequality inherent in war-some lives matter and others do not-is also important to reflect upon in relation to climate change; whose lives are and will be protected and whose are not considered grievable (Butler, 2004, p. 32).

While Butler is focused on the perspective of the human, I will extend the focus to also incorporate nonhuman elements, in this case, the built environment, taking some inspiration from an Actor-Network approach (Latour, 2005; Yaneva, 2009), as well as from Donna Haraway's 'Sympoiesis' (Haraway, 2016, p. 58), which means being creative together. Haraway argues that there is an urgent need for reshaping and moving the boundary between the 'critters' of planet earth and to work collectively for everyone to be able to coexist. According to Yaneva, non-human actors play a vital role in everyday decision-making by mediating agency, connecting, disconnecting, performing and enacting the different realities that make up everyday life.

The built environment and its thingy nature become a political actor when facilitating or hindering important decisions concerning climate change (Latour, 2017; Yaneva, 2017). For example, a bike lane mediates controversies that surround the built environment, its pedagogical possibilities, and the shift to climate-friendly lifestyles. Following a reinforced surface unfolds the various quotidian life situations where it operates and the many controversies (Yaneva, 2012) it takes part in, materializing wider notions such as safety and time planning in the everyday. Albena Yaneva writes about the building as a microcosmos (Yaneva, 2012, p. 26), which is a way to describe architecture as networks that consist of different actors, both human and non-human, that change over time. By tracing these networks, we learn not only about what the built environment does but also how it teaches us to behave in a situation. Even if these are different perspectives, they share the view that our lives are dependent on boundedness, to other humans and also non-humans, that is noncommunitarian, that somehow distorts the idea of proximity and distance and that places focus on the boundary itself rather than what it potentially separates and unites, a moral bond (Butler, 2004, p. 49; Haraway, 2016, p. 31; Yaneva, 2017, p. 29). These perspectives are important to the discussion of the responsibility of the individual and how she forms different assemblages that incorporate for example shame associated with climaterelated decision-making and how responsibility is somewhat shifting between humans and non-humans.

Primarily on social media such as Instagram and Facebook, environmental activists in Sweden have introduced the phenomenon of flygskam, which translates from Swedish to flight shame (Larsson, 2019; Mkono, 2019). It is an initiative aiming to make an individual feel ashamed for their habits associated with a cer- 
tain, more affluent lifestyle. In response to this, many Instagram users chose to show off their holiday travels by train instead.

Even if there is a risk of misinformation on both sides of the climate change debate, a tension is embodied in the social media and media coverage of activist Greta Thunberg (Jung, Petkanic, Nan, \& Hyun Kim, 2020), via whom a rising awareness of the general public has developed. The knowledge that drastic changes need to be made quickly to meet the requirements to lower $\mathrm{CO}_{2}$ emissions globally according to the Paris Agreement can cause 'eco-anxiety,' a high level of stress in the individual (Mkono, 2019). It emerges as a consequence of the clash between doomsday scenarios on the one hand and the unwillingness in some people to inform oneself on the other.

Within the debate on flight shame, it has been suggested that the ones that really should reconsider their lifestyle concerning climate change did not seem to care or understand their part. People tend to be optimistic and unaware of what part their individual lives play in the big picture. This aligns with the so-called 'optimism bias,' which means that we are less likely to believe that something bad will happen to ourselves than to someone else (Sharot, 2011). In some situations, this is helpful, but in this case, it complicates the understanding of our responsibility towards climate change. On the one end, there is the idea that every individual needs to act and change now and, on the other, there are the ones who feel that it does not matter at all what they do and that the responsibility lies elsewhere. The latter, expressed by an agitated participant in my survey, who also pointed to the very important point that everyone has different circumstances in their life that play important roles in everyday decision-making.

The responsibility to change rests on various shoulders: the individual, society, politicians, culture and so on, and it is, however, an ethical dilemma that links to care. Peg Rawes, drawing on Spinoza's writings on the 'common,' an aesthetic of care and wellbeing that he sees in shared patterns of human relations, describes how achieving a sense of wellbeing is not just a job for the individual citizen but also a greater concern for the larger group (Rawes, 2013, p. 51). Rawes studies the works of conceptual artist Agnes Denes who, for example, planted the Wheatfield: A Confrontation in Battery Park New York in the early 1970s as a critique and commentary on capitalist construction (Rawes, 2013, p. 41). Rawes sees a need, especially in urban environments, for mental as well as physical aspects of architecture to be addressed to achieve more general welfare in society (Rawes, 2013). To take care of one's own decisionmaking or one's dwelling can be motivated by how others take care of theirs. Maria Puig de la Bellacasa explains two important elements in care, the first is the aspect of an emotional connection to something and the second is the work associated with taking care of something (Puig de la Bellacasa, 2017, p. 42). The aspects of care are relevant both to decision-making itself and the potential affects that drive it.

In the questionnaires that I handed out, half of the respondents state that they have made transportation decisions prompted by climate shame and that their resolution to that problem has been firstly, to try as much as possible to use public transportation and secondly, to try to be clever when they use the car: pick up kids, do some shopping, and run errands so that they are efficient and minimise the frequency of car use. Why is it then that 9 out of 10 state that the car is the most used transportation means in their everyday life and that only 5 out of 14 are happy about that decision? Figure 2 depicts a vehicle situation for a resident of the part of Stångby built in the 1960 s.

\section{The Bike Lane}

To somewhat set the scene, let me describe a typical bike ride based on a route to work that one of the respondents recorded in the maps, a route that shared many similarities with the other bicycle commuters. It departs from the home and the destination is the workplace. When the commute begins, it passes through a residential area where the traffic is shared, an occasional car will appear, pedestrians of different ages walk by, its rhythm varies due to traffic lights, a tunnel, speed bumps, and so on. Upon arrival at the actual bike lane, the speed increases and consideration needs to be shown mainly to other cyclists, the bike lane runs parallel to the railroad, and a passing train might make a brief follower on the journey. Approaching the denser urban area, the bike lane narrows and the mix of modes of transportation presents itself anew. The bike lane continues for a bit, though narrower and with interruptions like pedestrian crossings and road crossings. The final stretch of the journey to work is on a street, through a park, crossing a major road with cars and public transport, and finally arriving at the bike stand next to the entrance to the workplace.

The trajectory described is accounted for in Figure 3 where the respondents' Wednesday routes are marked out superimposing one another. This example presents a problem-free day, where the choice to cycle is easily taken. Still, what are the circumstances that make the car such a common means of transportation? In the questionnaires and the comments in the margins of the maps, different problems were explained as reasons, such as the weather, temporal aspects, traffic problems, safety and issues related to the private economy. In the south of Sweden, where this study was conducted, the main obstacle given by the weather is wind, cold and rain, but some years, snow and ice may also cause problems for cyclists. The intention to cycle was a choice that would decrease one's carbon footprint, but it was hindered by the discomfort due to the climate. It is often argued that with the right attire, the weather is not an obstacle, but for many people it still is, and the weather has 


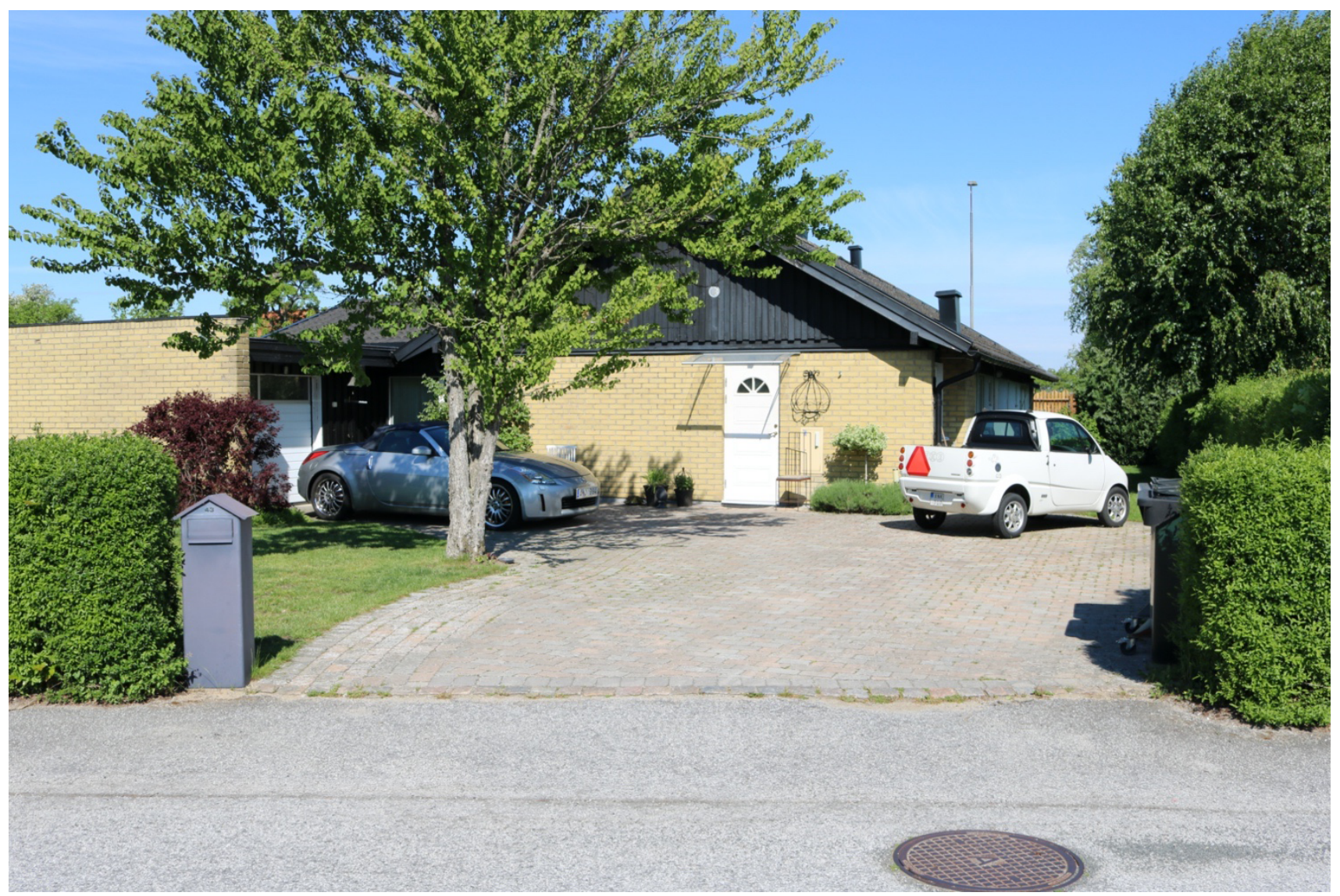

Figure 2. Cars in a driveway in the part of Stångby that was built in the 1960s. Source: Author.

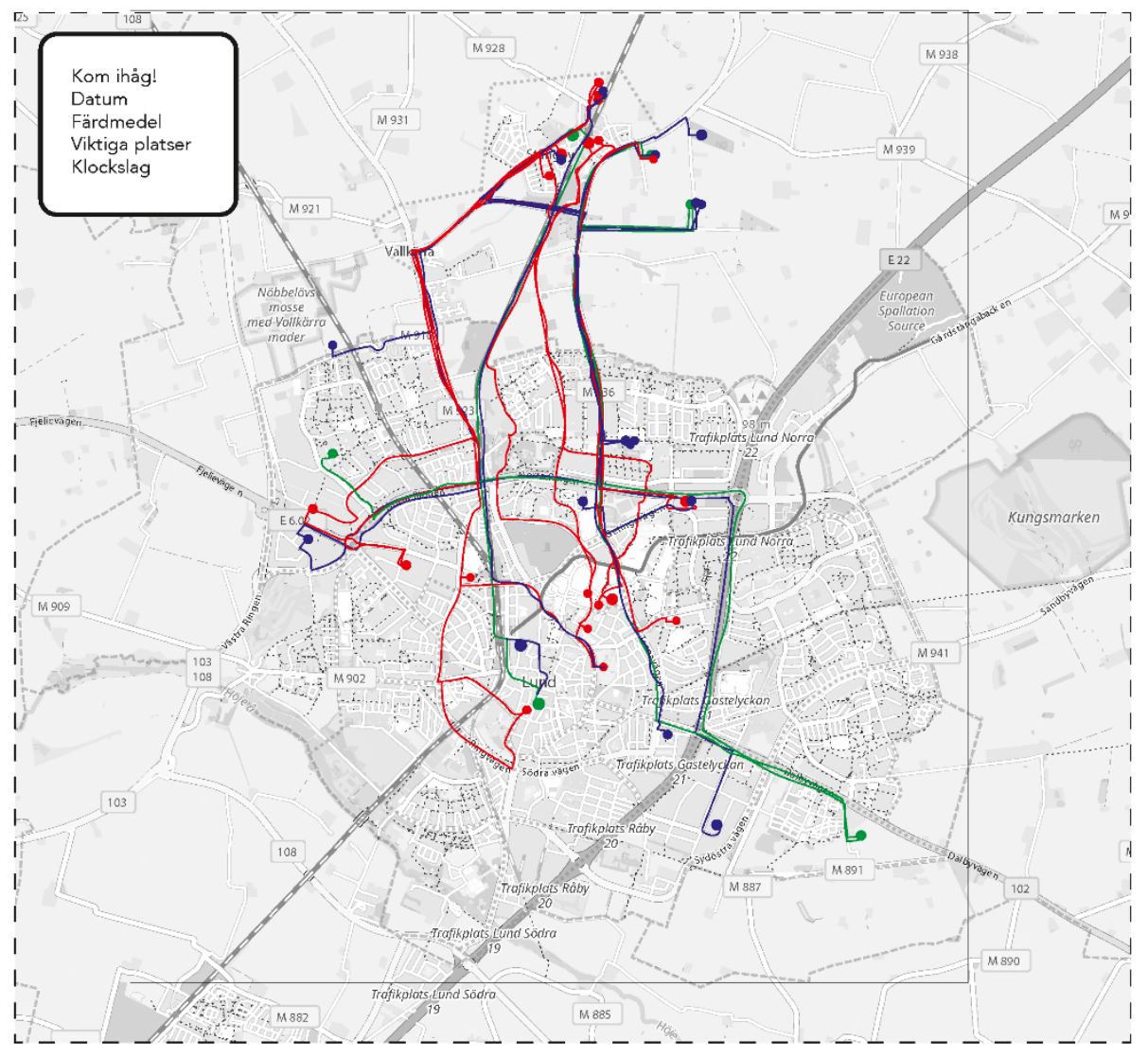

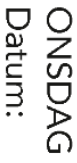

Figure 3. One of the maps from Wednesday, tracking the various routes of the respondents. Source: Author. 
always been challenging occasionally. The weather is a contingent and complicating factor in everyday decisionmaking, the choice to bike was taken from a place of care, for the planet and fellow inhabitants, both human and non-human. Where does the responsibility land here? One could say that it lands, at least to a certain extent, on designers and planners. There are microclimatic adjustments to be made in the built environment. However, many people will choose the car before the bicycle anyway, at least on a windy day with temperatures below 10 degrees.

Another aspect that affects choices made concerning daily transportation is time; it has most frequently come up in the respondents' answers as rush hours, evening/night, weekends and as a shortage of time/perceived stress. It was a dominant factor in decision-making related to public transport versus the car, where issues of public transport timetables, cancellations and crowdedness surfaced. Temporal aspects concerning riding the bike mainly addressed questions of security, of feeling unsafe riding in the dark and in deserted places at night or having to bike on shared roads with heavy traffic during rush hours. In this example, the responsibility is somewhat clearer, it is possible for policymakers, designers, planners, employers to work towards greater comfort by using means such as prioritisation, budgeting, working with lighting, scheduling, etc. These adjustments would benefit from looking at the built environment and its spaces concerning typical temporal situations such as rush hours. Puig de la Bellacasa writes: "Personal lives are both affected by what a world values and considers relevant and transformable through collective action. Thinking of practices of everyday care as a necessary activity to the maintenance of every world makes them a collective affair" (2017, p. 160). Along the lines of Puig de la Bellacasa, one could argue that choosing the bike is not only a personal preference but that if biking is fought for and made space for, it is also an act of environmental care.

\section{The Bike Ride That Did Not Happen}

There are some challenges to the daily transportation planning that is executed in the home. Traffic problems, especially for cars and public transport, contribute to decision making. In this case, the bike ride might be an alternative to the car or public transport. A recurring theme from informants is that they decide to choose something other than their preferred means of transportation due to fear of, for example, running late to a meeting or missing out on pick-up from school. This theme could couple with the temporal and is an example of moving responsibility, originating in the individual decision which is based on the fact that a bike lane exists and makes the ride possible. To use the terminology of Actor Network Theory, the built environment prescribes a certain mode of transportation via its material design, in relation to the climate change debate, even a moral mode of transport (Yaneva, 2009, p. 277). But at the same time, through its lack of certain elements, in the case of public transport punctuality or in the case of bike riding safety, it negates its own prescription and destabilises as a network (Latour, 1997, p. 176). The bike lane is not used for cycling even if it still exists as a material entity because it is perceived as unsafe.

The delegation of responsibility moves from the built world to actors such as policymakers, designers, planners and employers. The issue of safety was touched upon in relation to temporal aspects in some of the questionnaire's answers, though it does not present itself as the decisive force. Even if there is an ambition to choose alternatives to the car, if there is no bike lane and the road is narrow and densely trafficked, riding a bike or walking is not even an option. Again, the responsibility lies with the municipality and with designers. However, for them to even know the problem exists or that there is a wish for a bike lane to be built, civil organisations, activists, citizens and design-user-dialogues play important roles. In some cases, one is limited by expenses, the cost of public transport, of switching to a lowemission car, of buying an electric bicycle. One could argue that the responsibility is on the individual or politicians, on the municipality, large companies, or on employers. What becomes apparent in this situation is how limiting the network around the individual can be, and how this is the point where questions of social justice concerning new climate-friendly lifestyles are difficult to dodge. Who benefits from what we build and what resources does the individual need to make use of it? There is ethical potential in mapping the spatiotemporal assemblages that are shaped in relation to the cyclist because they show deficits in the designscapes of everyday transportation and social equality, what Rawes would call 'difference-relations' (Rawes, 2013, p. 52). Figure 4 shows a house from the old part of Stångby, dating back to the early 1900 s with bicycles parked outside the entrance.

All these obstacles to decision making produce a different affect. Shame and guilt are important, shame focuses more on the self and pushes us towards feeling bad whereas guilt is the notion of not being good in relation to other people; it pushes us to act morally. In some of the above examples, the individual is left with a sense of disempowerment, both towards the self but also in relation to other people. A dissonance emerges in the decision-making process as feelings of empowerment, good intentions and control are swayed by uncertainties in the context.

In the book Frames of War: When Is Life Grievable? Judith Butler (2016) connects guilt and the fears related to survivability. She wonders which decisions and actions we allow ourselves when our lives are threatened. She writes: "If guilt poses a question for the human subject, it is not first and foremost a question of whether one is leading the good life, but of whether life will be liveable at all" (Butler, 2016, p. 45). It accounts for a pro- 


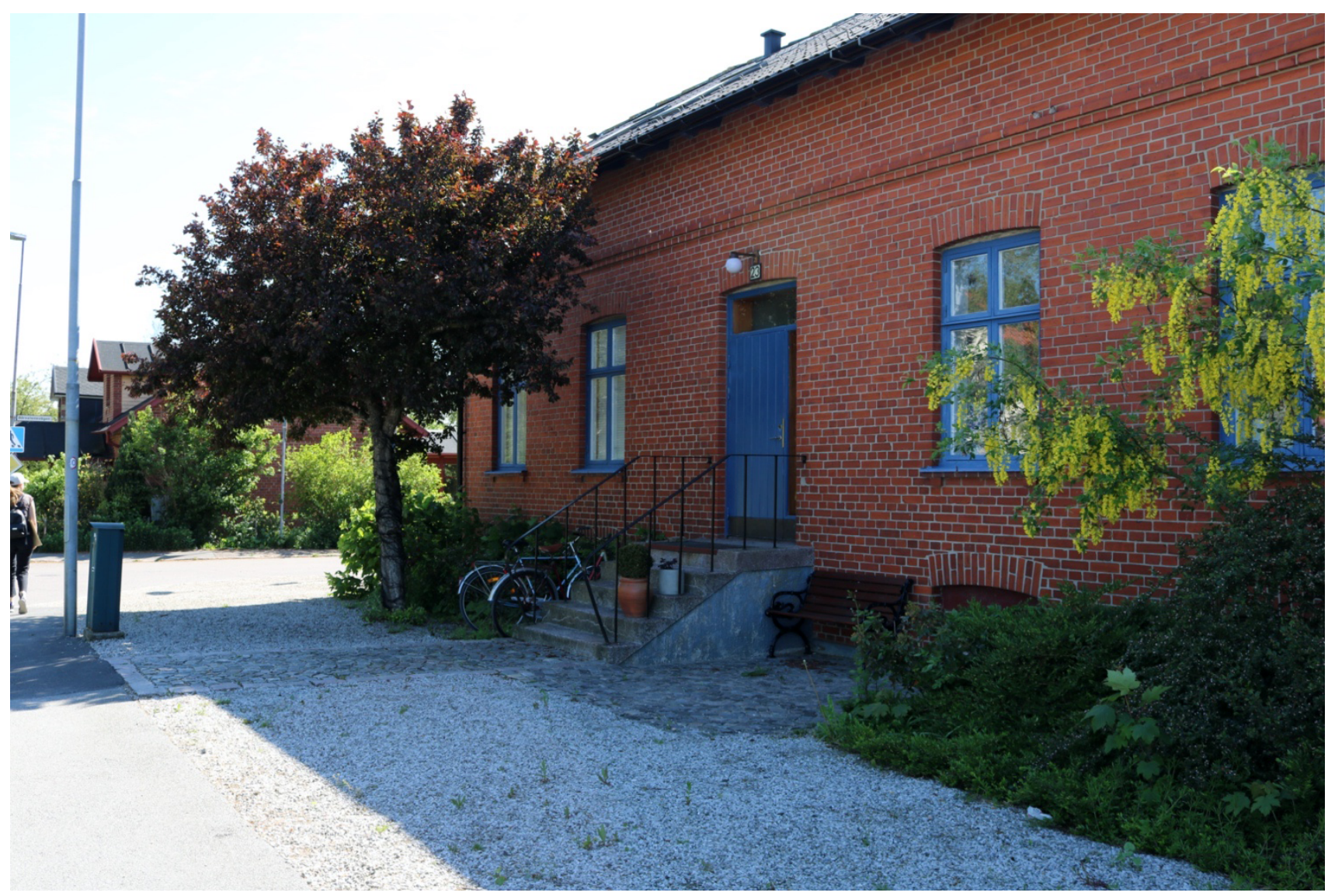

Figure 4. Bicycles parked outside a house in the old part of Stångby. Source: Author.

cess of moralisation. If one experiences guilt when faced with the possibility of ruining the lives of the ones with whom/which one is bounded, it is because of the instinct to protect one's own life. In the event of destruction of the life of the other, the one that my survival depends on, my destructive behaviour destroys not only someone else's but also my own chances to survive.

Guilt appears to incite a desire to self-help rather than a moral attitude towards the other. Even if feelings are activated towards fellow inhabitants, guilt appears deeply connected to the self (Butler, 2016). War operates on shorter timespans than climate change. However, the moral dilemma is shared between the problem realms. If I, coming from a place of discomfort or fear, act hastily and, for example, decide to preserve my lifestyle, I might cause harm somewhere else and over the years this harm will potentially come back to me.

The built environment is an important actor in the process, as it might just as well underscore a decision as it might make a decision completely impossible to carry out. In most cases, it provides both possibilities and problems. Let us stay with the bike lane. For example, in the situation with the bad weather, the bike lane lies there so the built environment complies with the decision to ride a bike. However, the icy wind makes the journey so unpleasant that the plan is discarded. It is possible for design elements and technological advancement to make the experience nicer, but a major issue of the built fabric might be distance; the length of the commute is decisive as to whether or not one will endure the climate or not. So, it is a question of how things are built, but foremost of how they are laid out in relation to one another and how creative the individual can be in terms of adjusting the day to, for example, work closer to the home or not. For example, the opportunity to be flexible and work from home on days with harsh weather can then form part of the bike riding program and the choice to cycle as a moral act for the future of the planet can be sustained. Albena Yaneva writes:

Design makes us gain access to the social, but it is a molecularised social, discovered in individual objects, users, designers and inventors. If many individual users like me do not repeat what design has implied, nothing remains of the social. (Yaneva, 2009, p. 282)

For the bike order to be socially upheld, the network relations between the material elements of the bike ride and its repeated use needs to incorporate flexibility. The responsibility slides away from the individual who might be shameful for not choosing the bike, even if most of us are rather powerless when faced with some of the circumstances.

According to answers in questionnaires and comments written on the maps, the time-related hinders to using the bike lane are connected to the individual and 
are more likely to invoke guilt considering how these choices are usually made in relation to oneself and based on perhaps fear of the dark, discomfort in crowds, the stress of having a busy life with many activities and so on. Even though there is a bike lane, the bike remains unused in the stand. Numerous urban design strategies could enable a more climate-friendly decision regarding transportation, for example, to work with lighting, openness, a mix of activities but this example also shows how intricate the relationship between the built environment and the responsibility of for example policy and employers is. Flexibility and autonomy are important to be able to make the best use of the bike lane in relation to these problems. Traffic problems were reported to cause a lot of stress in everyday life, the discomfort of being in a tight situation and the fear of not making it in time for meetings for example. However, in the answers, this is mentioned mostly concerning cars and public transport and can therefore be the element that pushes towards taking the bicycle instead, depending on how far your day-today destination is.

The response with less embedded dissonance that came up several times was safety. If an option is better for the climate but means risking your life, it does not chafe very much, 'I could make a choice, but I am not able to execute it.' Cycling or walking is not an alternative if there is no safe way. The last example that was mentioned in the questionnaires is about the private economy in the responses expressed as 'I would prefer to choose differently but I cannot afford it.' A structural and common problem especially in everyday ethical consumption decisions (Hall, 2011) is that even if the built environment matches the preferred mode of transport, the individual is left feeling disempowered and perhaps shameful.

These examples show that shame can make pushes towards moral decisions and that the built environment plays an important role in the possibility to make changes in everyday transportation. To make changes in your life might require a time of mourning for the past while welcoming the present, a sense of loss that becomes necessary for transformation to take place (Butler, 2004, p. 21). An asphalted stretch of road gives information about the interconnections between material architectural elements and the small and large networks that our daily lives are made up of. Shame can push us towards trying something new and guilt reminds us of the difficulties that occur on the path between the choice to change and the final execution of the new plan.

\section{Ethical Responsibility}

This brings us to a discussion on the responsibility of the individual, the role of a built element such as the bike lane and the possibility for an architecture of care. The individual has responsibility for everyday life decisions but there needs to be a framework around her to enable change. In social media, the flight shaming movement has taken place, advocating new social norms in relation to one's personal carbon footprint (Gössling, Humpe, \& Bausch, 2020). Examples of initiatives to lifestyle changes taken by individuals have appeared in the local newspaper with examples of how one can adjust something small like changing the speed at which you drive your car on the freeway to reduce your overall $\mathrm{CO}_{2}$ emissions. There have also been different examples of downshifters (Juniu, 2017) who proclaim the need to place value on time rather than on commodities. Affect such as shame and guilt may be strong means to induce transition but there has to be possibilities for them to work and to not be destructive.

One way towards a common commitment to align our everyday lives in a more climate-friendly manner is to recognise that no one can escape the precarity that comes with social life, it may be considered our shared non-foundation (Butler, 2011, p. 21). One can push people in different directions but also need to provide possibilities for them to make changes: The relations between individuals, the built environment, and policy are intricate. This is illustrated in the different ways the bike lane mediates agency to the user and also conveyed in Figure 5 with the driveway suggesting that its owner buys a car. The media reports on wildfires, hurricanes, melting ice and plastic agglomeration can be terrifying. Butler describes it, drawing on Susan Sontag, as a way to make faraway suffering close and what is proximate far away, the images of distant suffering impose an ethical interrogation on us as viewers that compels us to treat questions of proximity. Do I contribute to the occurrence of this suffering? She means that ethical obligations span across time and space (Butler, 2016, pp. 68-69). Shifting our everyday means of transportation might be a more sustainable lifestyle for us but it can also be an act of care for the rest of the world and all its inhabitants.

By caring for someone or something, we work in relation to a larger collective, thereby adding an ethical dimension to our everyday lives (Puig de la Bellacasa, 2017, p. 160). Ethical dilemmas may arise out of the ordinary (La Cecla \& Zanini, 2013), in this study via a sample of weeks of someone's daily transportation routes. Whether one acknowledges it or not, there is a moral bond between human beings, the ones that exist in close physical proximity and the ones that are far away. It is tempting to use a broad-brushed 'we' here but let us try to resist it and remain focused for the concluding part of the text. Judith Butler argues that the precondition for the 'we' is to find out how we are interconnected as fellow humans (Butler, 2004, p. 49). For me to understand who you are and to get to know you, I must lose myself and rebuild myself in relation to the other, this process takes place repeatedly throughout life. The city is described similarly by Albena Yaneva $(2017$, p. 91$)$ as multiple realities that are reproduced in different contexts over and over again.

As citizens, we need to understand the connections that we take part in on different levels, different spa- 


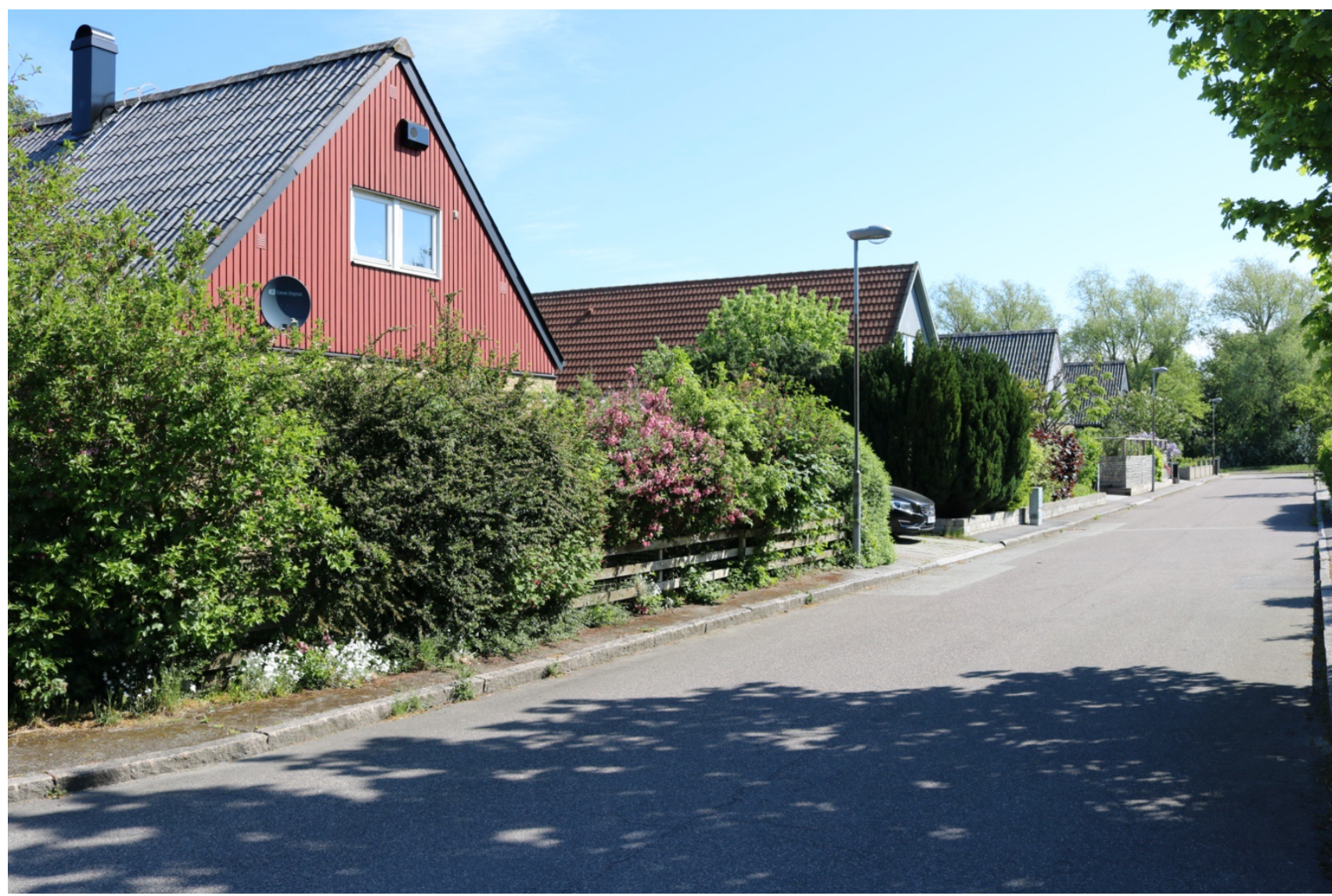

Figure 5. Single-family housing in the part of Stångby built in the 1960s, where every single unit has a driveway to park the car. Source: Author.

tialities and different temporalities. This article suggests that we may start with what is right in front of us: the bike lane. My actions have many different effects simultaneously; what I decide to do in my everyday life is inevitably a part of someone else's life, my decisions form a boundary for me and at the same time an adjacency to the other (Butler, 2011). It is important to understand this in decision-making processes. How I articulate myself as a subject becomes important in relation to the world around me (Butler, 2004, p. 44) and thereby my actions and their effects on the close and distant world. Shame can be a functional tool to raise awareness of my role in larger processes but can also underscore a sense of powerlessness if it is difficult to carry out a transformation. There appears to sometimes be a dissonance between the level of knowledge about the role that I have acquired concerning climate change and the space in my everyday life to change.

\section{Concluding Remarks}

With Covid-19, the beginning of 2020 has interestingly shown how fast a large transition can be made once the policy is in place. Possibilities open up for employers and individuals to adjust their everyday routines and facilitate changes that can be climate-friendly such as avoiding frequent long-distance travelling, flexibility to work from home and to learning new ways to be social. Nevertheless, the planning, design and construction of roads, bike lanes, parking lots, bus lanes, stations, benches, and so on need to be synchronised with larger systems for citizens to be able to make climate-friendly transportation decisions in their everyday life.

Although the sample in the empirical study was relatively small, some aspects turned out to be more important than others in relation to the specific suburb that I have studied. For the majority of participants who responded, transportation possibilities had been a parameter upon deciding to move there. Access to public transportation and the relatively short distance to Lund were crucial points. Most of the respondents had both the means and strong ambitions in terms of reducing their ecological footprint through transportation but still many felt that for different reasons such as synchronisation of activities, costs or security, that they were highly dependent on the car. Another somewhat banal, but still very important, result is that in the absence of a bike lane, most of the respondents did not ride a bike even if they would have liked to. However, as this discussion has shown, the bike lane moves in and out of different socio-material assemblages over time. Even if cycling was the main mode of transport, it would not be the only means of transport in the respondents' everyday. Daily transportation has here presented itself not as a mere 
spatial problem but also a temporal one and it appears as if there is need for a synchronised arsenal of accessible climate-friendly options to transport. In total, there are improvements to be made for the residents of Stangby and other similar places.

One aspect that seems interesting to investigate further concerning future ethical living spaces might be time-planning. Time-planning was introduced to address problems within the complex urban landscape such as crowding, gridlocks, accessibility and so on (Fernandes et al., 2015; Mareggi, 2002). My study suggests that these kinds of initiatives could perhaps be put to use more explicitly also when it comes to everyday life choices relating to sustainable development and a way of living that addresses the gap that arises between climatefriendly intentions on the one hand and everyday life hindrances on the other. Working with temporal aspects would facilitate flexibility. The view that time is inseparable from architecture (Till, 2009, p. 116) is a way to understand how transition is not necessarily about tearing something down and replacing it with something new but rather about acknowledging how it, for example, is and can be used differently over time, shifting throughout the day, the week, a month, a year and so on. Thus, planning must be complemented with a focus on material design. In Sweden, safety issues have, for example, made it into planning but have also affected urban design on quite detailed levels, discussing both problems that spring from asymmetric power relations (Listerborn, 2002, 2015), and connecting these to practical directives including maintenance of shrubbery, light design, etc. Something similar might be necessary if we would like to address the ethical concerns regarding everyday decision-making brought up in this article. Different entities of the built environment, including paving materials, shelters for the wind, etc., are important actors if we want to stabilise the bike trip as a recurrent event. This cannot be left to planning to handle but needs to be materialised and designed on different scale levels.

An architecture of care (Rawes, 2013, p. 52) should be designed departing from individuals' and society's needs and, when in place, it holds a pedagogical potential to show possibilities concerning how to structure everyday life. The back and forth movement between use and planning is important for design not to give way solely to nudging (French, 2011). Urban design can play a role by being discussed contextually. The bike lane has shown how the relationship between the user and the built environment is not a one-way affair, rather, it gives and takes and materialises repeatedly. A possible climate friendly path regarding ethical everyday interactions between the built environment and its users is inspired by the notion of 'care,' a creative togetherness, something that needs to be investigated further. The assemblages that form and vary over time, that one moves in and out of, shows that there is a shared and moving responsibility between material elements and users.

\section{Acknowledgments}

The research for this article was made possible thanks to the FORMAS financed research project "Urban Design and Everyday Life Choices: On the Built Environment as a Co-Producer of Climate Ethics" (2017-01943). Thank you to all the respondents who participated in the empirical study, I am very grateful for your contribution.

\section{Conflict of Interests}

The author declares no conflict of interests.

\section{References}

Butler, J. (2004). Precarious life: The powers of mourning and violence. New York, NY: Verso.

Butler, J. (2011, May 27). Judith Butler: "Precarious life: The obligations of proximity" [Video file]. Retrieved from https://www.youtube.com/watch? $\mathrm{v}=$ KJT69AQtDtg\&ab_channel=NobelPrizeMuseum

Butler, J. (2016). Frames of war: When is life grievable. London and New York, NY: Verso.

Fernandes, J., Chamusca, P., Frago, L., Gasnier, A., Kärrholm, M., \& Pujol, C. (2015). Time policies, urban policies and planning. GOT: Revista de Geografía e Ordenamento do Território, 7, 129-157.

French, J. (2011). Why nudging is not enough. Journal of Social Marketing, 1(2), 154-162.

Gössling, S., Humpe, A., \& Bausch, T. (2020). Does 'flight shame' affect social norms? Changing perspectives on the desirability of air travel in Germany. Journal of Cleaner Production, 266. https://doi.org/10.1016/ j.jclepro.2020.122015

Hall, S. M. (2011). Exploring the 'ethical everyday': An ethnography of the ethics of family consumption. Geoforum, 42, 627-637.

Haraway, D. (2016). Staying with the trouble, making kin in the chthulucene. Durham, NC: Duke University Press.

Jung, J., Petkanic, P., Nan, D., \& Hyun Kim, J. (2020). When a girl awakened the world: A user and social message analysis of Greta Thunberg. Sustainability, 12(7). https://doi.org/10.3390/su12072707

Juniu, S. (2017). Downshifting: Regaining the essence of leisure. Journal of Leisure Research, 32(2), 69-73.

La Cecla, F., \& Zanini, P. (2013). The culture of ethics. Chicago, IL: Prickly Paradigm Press.

Larsson, R. (2019). Framing and shaming: A case of opinion leadership and climate change communication in a social media era. A frame analysis of the Swedish Instagram account Aningslösa influencers (Master dissertation). Faculty of Culture and Society, Malmö University, Sweden.

Latour, B. (1997). Trains of thought: Piaget, formalism and the fifth dimension. Common Knowledge, 6(3), 170-191.

Latour, B. (2005). Reassembling the social, an introduc- 
tion to actor-network-theory. New York, NY: Oxford University Press

Latour, B. (2017). Down to earth, politics in the new climatic regime. Cambridge: Polity Press.

Lee, H. (2002). To kill a mockingbird. New York, NY: HarperCollins Publisher. (Original work published 1960)

Listerborn, C. (2002). Trygg stad-Diskurser om kvinnors rädsla i forskning, policyutveckling och lokal praktik [Safe city: Discourses on women's fear in research, policy development and local practices]. Gothenburg: Sektionen för Arkitektur.

Listerborn, C. (2015). Geographies of the veil: Violent encounters in urban public spaces in Malmö, Sweden. Social \& Cultural Geography, 16(1), 95-115.

Mareggi, M. (2002). Innovation in urban policy: The experience of Italian urban time policies. Planning, Theory \& Practice, 3(2), 173-194.

Mkono, M. (2019). Eco-anxiety and the flight shaming movement: Implications for tourism. Journal of
Tourism Futures. Advance online publication.

Puig de la Bellacasa, M. (2017). Matters of care: Speculative ethics in more than human worlds. Minneapolis, $\mathrm{MN}$ : University of Minnesota Press.

Rawes, P. (2013). In relational architectural ecologies: Architecture, nature and subjectivity. Abingdon and Oxon: Routledge.

Sharot, T. (2011). The optimism bias. Current Biology, 21(3).

Till, J. (2009). Architecture depends. Cambridge, MA: MIT Press.

Williston, B. (2019). The ethics of climate change: An Introduction. Abingdon and Oxon: Routledge.

Yaneva, A. (2009). Making the social hold: Towards an actor-network theory of design. Design and Culture, 1(3), 273-288.

Yaneva, A. (2012). Mapping controversies in architecture. Farnham: Ashgate.

Yaneva, A. (2017). Five ways to make architecture political. London and New York, NY: Bloomsbury.

\section{About the Author}

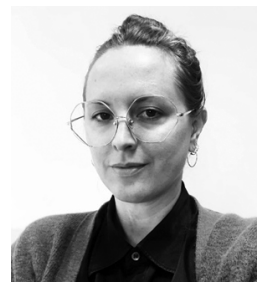

Paulina Prieto de la Fuente has an MA in Architecture and is currently a Postdoc at the Department of Architecture and Built Environment, Lund University. Her research started in 2010 as an Assistant in a project about consumption, shopping centres, and public space. She continued with her PhD project that focused on formlessness and chronopolitics in what she calls rhythm architecture which she studied in a public square in Malmö, a city in the south of Sweden. Prieto's current research revolves around the relationship between the built environment and climate ethics. 